\title{
Evaluation and Correction of the Ambient Particle Spectral Light Absorption Measured Using a Filter-based Aethalometer
}

\author{
Gang Zhao ${ }^{1,3}$, Yingli Yu${ }^{1}$, Ping Tian ${ }^{2}$, Jing $\mathrm{Li}^{1}$, Song, Guo ${ }^{3}$, Chunsheng Zhao ${ }^{*}$ \\ ${ }^{1}$ Department of Atmospheric and Oceanic Sciences, School of Physics, Peking University, Beijing 100871, China \\ ${ }^{2}$ Beijing Key Laboratory of Cloud, Precipitation and Atmospheric Water Resources, Beijing 100089, China \\ ${ }^{3}$ College of Environmental Sciences and Engineering, Peking University, Beijing 100871, China
}

\begin{abstract}
Spectral light-absorption properties measured with an Aethalometer (AE; Model AE33; Magee Scientific) are widely used in radiative forcing studies and source appointment in China. However, considerable uncertainty regarding the measured absorption coefficient $\left(\sigma_{a b s}\right)$ exists because of the multiple-scattering effects, loading effects, and differences in filter tape. This study evaluated $\sigma_{a b s}$ by comparing the values measured with an AE33 using Tape 8050, an AE33 using Tape 8060 (which differs from Tape 8050 in material), and a three-wavelength photoacoustic soot spectrometer (PASS-3) during two field campaigns in eastern China. The results indicated that the AE33-measured $\sigma_{a b s}$ using either tape exceeded the PASS3-measured value by approximately three times, mainly owing to the multiple-scattering effect. A wavelength-independent multiple-scattering compensation factor (2.90), which varies slightly $( \pm 0.04)$ for eastern China, is recommended for these regions. When $\sigma_{a b s}$ was measured with the AE33 using Tape 8050, the value highly depended on the loading on the tape, which led to significant uncertainty and discontinuity in the absorption Ångström exponent compared to using Tape 8060. A method was proposed to effectively correct the historical datasets of $\sigma_{a b s}$ and the absorption Ångström exponent by using the AE33 with Tape 8050. This work provides insight into the quality of measured absorption data when filter-based measurement technology is applied.
\end{abstract}

Keywords: Black carbon; Absorption; Multiple-scattering compensation; Loading effects.

\section{INTRODUCTION}

Light-absorbing particles exert considerable effects on aerosol radiative force by absorbing radiation, changing the aerosol single-scattering albedo and interacting with clouds (Koch and Del Genio, 2010; Bond et al., 2013). Black carbon (BC) dominates the light absorption of atmospheric particles (Saturno et al., 2017). Ice and snow albedos can be markedly changed when $\mathrm{BC}$ particles are deposited on them (Bond et al., 2013), which leads to great uncertainty when estimating aerosol climate effects. Absorbing aerosols can also influence the environment by suppressing turbulence in the atmospheric boundary layer (Wilcox et al., 2016).

Considerable uncertainty may also arise regarding radiative effects when the light-absorbing ability is measured at one wavelength or over a limited range because ambient aerosol light absorption is dependent on wavelength. The absorption Angström exponent $\left(\alpha_{a b s}\right)$ ( ̊ngström, 1929) is used to describe the ae rosol light-absorption property as follows:

\footnotetext{
* Corresponding author.

E-mail address: zcs@pku.edu.cn
}

$$
\frac{\sigma_{a b s}\left(\lambda_{1}\right)}{\sigma_{a b s}\left(\lambda_{2}\right)}=\left(\frac{\lambda_{1}}{\lambda_{2}}\right)^{-\alpha_{a b s}}
$$

where $\sigma_{a b s}\left(\lambda_{1}\right)$ and $\sigma_{a b s}\left(\lambda_{2}\right)$ are the absorption coefficient at wavelength $\lambda_{1}$ and $\lambda_{2}$ respectively. Different characteristics of wavelength dependence are observed for different aerosol types (Schmid et al., 2006). The theoretical $\alpha_{a b s}$ values of BC from the fuel is 1.0 (Martinsson et al., 2017) whereas some organic absorption classes have $\alpha_{a b s}$ values spanning a wide range between 3.5 and 7.0 (Schmid et al., 2006). Thus, spectral light-absorption information can provide knowledge regarding the source and aging process of ambient aerosols (Zotter et al., 2017).

Many methods have been developed to measure spectral light-absorbing properties, and these methods have been well summarized and described by Bond et al. (2013) and Petzold et al. (2013). Filter-based instruments, such as Aethalometers (AEs) (Hansen et al., 1984), Particle Soot Absorption Photometers (Bond et al., 1999) and Multi-Angle Absorption Photometers (Petzold and Schönlinner, 2004), are widely used for both ground measurements and airborne studies because they are easy to operate (Coen et al., 2010). The $\sigma_{a b s}$ at different wavelengths is obtained by measuring 
the attenuation of light when it passes through an aerosolladen filter. AEs are the most frequently used commercial instruments to measure ambient aerosol $\sigma_{a b s}$. However, it is necessary to post-process AE-measured data to compensate for the well-known multiple-scattering effects and loading effects (Bond et al., 1999; Coen et al., 2010). Ample effort has been devoted to the methods of correcting measured $\sigma_{a b s}$ (Coen et al., 2010; Virkkula et al., 2015; Saturno et al., 2017). Recently, a new dual-spot Aethalometer (AE33), which measures $\sigma_{a b s}$ at seven different wavelengths from $370 \mathrm{~nm}$ to $950 \mathrm{~nm}$ with real-time loading effects compensation, was developed (Drinovec et al., 2015).

The official filter tape of AE33 has been changed from Model 8050 to 8060 because the nonlinear filter-loading effect from Tape 8050 causes dysfunction in the compensation process. Although AE33 with Tape 8050 has long been used for measurement worldwide, the performance of measured $\sigma_{a b s}$ is not well characterized. It is widely accepted that the uncorrected $\sigma_{a b s}$ data from AE33 is too high and that correction of the multiple-scattering effect is necessary (Moosmüller $e t$ al., 1998; Saturno et al., 2017; Sharma et al., 2017). Moreover, the $\sigma_{a b s}$ measured with Tape 8050 is unstable, and the loading effects of the measured $\sigma_{a b s}$ are not satisfactorily corrected, which was confirmed in this study. Furthermore, there have been more than 30 AE33 instruments employed to measure ambient $\sigma_{a b s}$ in China since 2015 (personal communication), and these data are used to infer information regarding $\mathrm{BC}$ emissions in China. However, these data require reconstruction to accurately reveal the light-absorption properties of ambient aerosol.

In this study, we evaluated measured $\sigma_{a b s}$ by using AE33 with Tape 8050 and Tape 8060 from two field measurements in eastern China. Based on the inter-comparison of the measured $\sigma_{a b s}$ from AE33 and a three-wavelength photoacoustic soot spectrometer (PASS-3), a wavelength-independent multiple-scattering correction factor $\left(\mathrm{C}_{f}\right)$ value was recommended for eastern China. Using the same correction factor of 2.9 for eastern China makes it easier to reconstruct the historical observation data measured by AE33.

\section{MEASUREMENTS AND INSTRUMENTS}

\section{Measurement Sites}

The field measurements were conducted at two sites: Peking University (PKU) and Taizhou. The suburban measurement at site Taizhou $\left(119^{\circ} 57^{\prime} \mathrm{E}, 32^{\circ} 35^{\prime} \mathrm{N}\right)$, as shown in Fig. 1(a), lies at the south end of the Jianghuai Plain in eastern China. It is located approximately $118 \mathrm{~km}$ southeast of the megacity Nanjing and approximately $200 \mathrm{~km}$ northeast of another megacity, Shanghai. The industrial area between Nanjing and Shanghai has experienced severe pollution over the past 30 years. The average aerosol optical depth at the wavelength of $550 \mathrm{~nm}$ during 2017, as measured by the Moderate Resolution Imaging Spectroradiometer, indicates that the measurement site is more polluted than the surrounding area (Fig. 1(b)). Taizhou is a representative location polluted mainly by secondary organic aerosol and biomass burning in eastern China (Zhao et al., 2019a). The PKU site is located northwest of Beijing, between the Fourth and Fifth Ring Road. It is $11 \mathrm{~km}$ away from the center of the Beijing, which is surrounded by Hebei Province and the megacity Tianjin. The Beijing-Tianjin-Hebei region suffers from heavy air pollution due to various industrial activities. As revealed in Fig. 1(b), the PKU site is on the edge of the heavily polluted area of the North China Plain. Datasets for this location are representative of the urban aerosol pollution in the North China Plain (Guo et al., 2012; Guo et al., 2013; Tang et al., 2018; Zhao et al., 2018; Zhao et al., 2019b).

Measurements at the PKU site were recorded in the spring (March 20-April 30) and in the autumn (October 10-19) of 2018, whereas observations at the Taizhou site took place in the summer (May 22-June 17) in 2018. For both sites, all of the instruments were placed in a container, in which the temperature was well controlled within $24 \pm 2{ }^{\circ} \mathrm{C}$. The
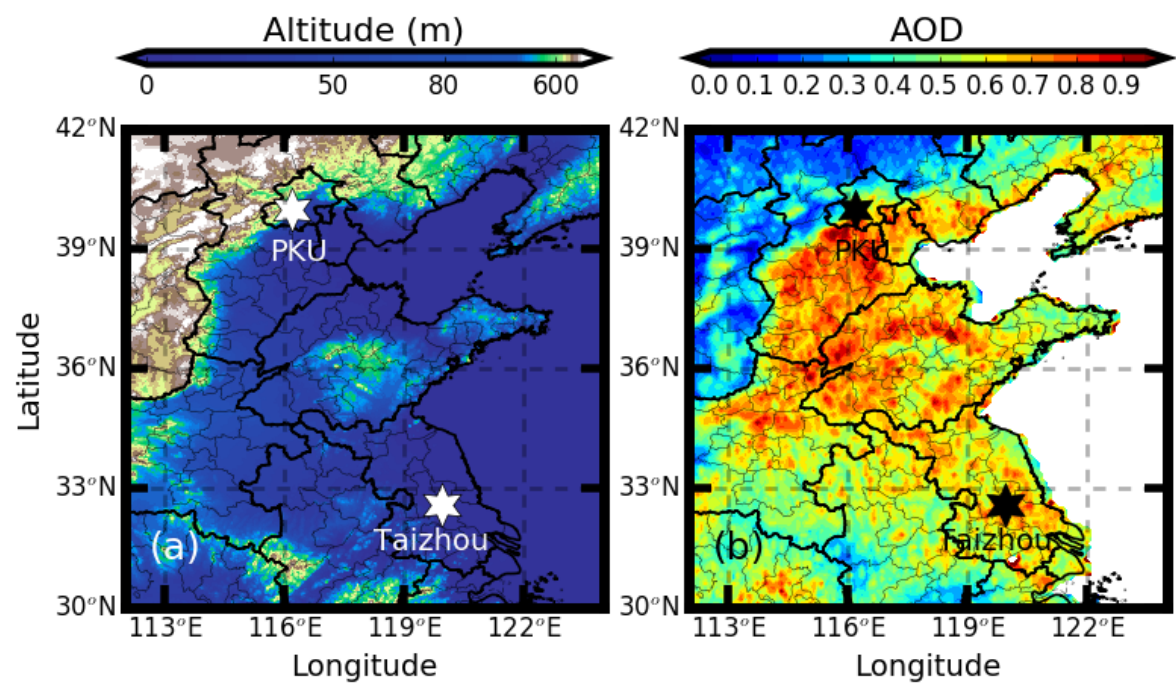

Fig. 1. Measurement sites of Taizhou and PKU (marked with a hexagonal star). Filled colors represent (a) the topography of eastern China and (b) the average aerosol optical depth at $550 \mathrm{~nm}$ during 2017 from the Moderate Resolution Imaging Spectroradiometer on board the Aqua satellite. 
sample air was collected using a $\mathrm{PM}_{10}$ impactor (Model SSI2.5; Mesa Labs) mounted on top of the container. Next, the sample air was passed through a Nafion dryer tube. The relative humidity of the sample particles measured with each instrument was controlled below $30 \%$.

\section{Instruments}

The instruments used for the two field measurements are listed in Table S1. The corresponding time periods when data were available are marked in blue. The $\sigma_{a b s}$ was measured by the PASS- 3 at three wavelengths $(405,532$, and $781 \mathrm{~nm})$ and by two AE33s with different types of filter tape at seven wavelengths $(370,470,520,590,660,880$, and $950 \mathrm{~nm}$ ). The two AE33s had the serial numbers 0345 and 0582 and were labeled as AE33-345 and AE33-582, respectively. The aerosol scattering coefficient $\left(\sigma_{s c a}\right)$ was measured using an Aurora 3000 nephelometer (Müller et al., 2011) at wavelengths of 450, 525, and $635 \mathrm{~nm}$. Data correction was performed following Müller et al. (2011). The aerosol particle number size distribution (PNSD), ranging from $20 \mathrm{~nm}$ to $10 \mu \mathrm{m}$, was measured by using the Scanning Mobility Particle Size spectrometer (SMPS; Model 3936; TSI Inc.) and Aerodynamic Particle Sizer (APS; Model 3321; TSI Inc.).

Because the SMPS and APS provided the aerosol PNSD data every 5 minutes, all $\sigma_{a b s}$ and $\sigma_{s c a}$ data were averaged with the same time resolution of 5 minutes for further study.

\section{PASS-3}

The principle of PASS- 3 has been described elsewhere (Terhune and Anderson, 1977; Utry et al., 2014; Nakayama et al., 2015; Cremer et al., 2017; Davies et al., 2018), and thus only a brief introduction is presented here. First, the PASS3 continuously pumps the sample aerosol into an acoustic resonator, and these absorbing aerosols are irradiated by laser lights at 405, 532 and $781 \mathrm{~nm}$. The laser is an amplitudemodulated square wave with a frequency of $1500 \mathrm{~Hz}$. The absorbing aerosols absorb light energy and then generate periodic pressure waves in the resonator. Finally, $\sigma_{a b s}$ is retrieved from the amplitude of the pressure wave by using a microphone. The PASS-3 installs a scattering integrating sphere to measure the aerosol $\sigma_{s c a}$ concurrently with the $\sigma_{a b s}$.

The PASS-3 is capable of measuring the $\sigma_{s c a}, \sigma_{a b s}$, and the extinction coefficient $\left(\sigma_{\text {ext }}\right)$ independently for high aerosol concentrations, which makes it easy to calibrate (Terhune and Anderson, 1977; Davies et al., 2018). In our study, $\sigma_{s c a}$ of the integrating sphere was calibrated using pure scattering aerosol ammonium sulfate, and $\sigma_{a b s}$ was calibrated using Aquadag soot particles by subtracting $\sigma_{\text {ext }}$ from $\sigma_{s c a}$. The PASS- 3 can provide $\sigma_{a b s}$ data with high accuracy if it is properly calibrated (Davies et al., 2018). The uncertainty of the absorption measurements was estimated to be $4 \%, 8 \%$, and $11 \%$ from 405, 532, and $781 \mathrm{~nm}$, respectively (Nakayama et al., 2015). Several studies have used $\sigma_{a b s}$ data measured by a PASS as reference to evaluate the $\sigma_{a b s}$ measured by a filter-based instrument (Arnott et al., 2005; Schmid et al., 2006; Lack et al., 2014; Utry et al., 2014).

Here, calibration of the PASS-3 was conducted at the beginning of field observations at the PKU site, and at the beginning and near the end of the observations at the Taizhou site. The status of the instrument did not exhibit considerable change, and the variations of the calibrated parameters were within $3 \%$. Thus, the calibration results at the beginning of the measurement were used to derive the observations for each site.

\section{$A E$}

The AE is a well-designed instrument that is used to measure the light intensity transmitted through a fiber filter on which the aerosols are deposited (Masey et al., 2020). The filter attenuation (ATN) is calculated as:

$$
A T N=100 \cdot \ln \left(\frac{I_{0}}{I}\right)
$$

where $I$ and $I_{0}$ are the concurrently measured light intensities that pass through the fiber with and without aerosol loading, respectively. The aerosol attenuation coefficient $\sigma_{A T N, 0}$ can be calculated as follows:

$\sigma_{A T N, 0}=\frac{A \cdot \Delta A T N}{100 \cdot F \cdot \Delta t}$

where $\triangle A T N$ is the change in ATN over time period $\Delta \mathrm{t} ; A$ is the sample spot area, and $F$ is the aerosol flow rate. The $\sigma_{A T N, 0}$ values are corrected as $\sigma_{A T N}$ after filter-loading correction. The AE33 model succeeds in correcting the loading effects by performing real-time measurements of two parallel spots at different flow rates. More details on correcting the loading effects by using AE33 are provided by Drinovec et al. (2015). In this study, the corrected attenuation coefficient $\sigma_{A T N}$ from the AE33 was compared with the $\sigma_{a b s}$ measured using the PASS-3.

\section{RESULTS AND DISCUSSION}

\section{Measurement and Model of the Aerosol Scattering Coefficient}

The PASS-3 is capable of measuring aerosol $\sigma_{s c a}$ and $\sigma_{a b s}$ concurrently. We first proved the reliability of the measured $\sigma_{s c a}$ by using the PASS-3, after which the reliability of the measured $\sigma_{a b s}$ by the PASS-3 was guaranteed. The $\sigma_{s c a}$ values measured by the PASS-3, measured by a nephelometer and calculated using the scattering model with measured aerosol PNSD were compared first. The data used were obtained from the measurements at the PKU site. Comparison within the Taizhou site yielded results that were almost the same.

The Mie scattering model (Bohren and Huffman, 2007) was employed to calculate the $\sigma_{s c a}$ at different wavelengths. When running the Mie scattering model, the aerosol PNSD and $\mathrm{BC}$ mass concentration were required. The $\mathrm{BC}$ mass concentrations were calculated using the corrected $\sigma_{a b s}$ from the AE33 at a wavelength of $880 \mathrm{~nm}$, with the assumption that the mass absorption coefficient was $7.77 \mathrm{~m}^{2} \mathrm{~g}^{-1}$. All of the BC particles were also assumed to have mixed internally with other aerosol components. The refractive indices of $\mathrm{BC}$ and non-light-absorbing aerosols are $1.8+0.54 \mathrm{i}$ (Wex et al., 2002; 
Kuang et al., 2015) and $1.53+10^{-7}$ i (Wex et al., 2002) respectively. With this information, $\sigma_{s c a}$ at different wavelengths can be calculated. More details regarding this calculation process can be found in Zhao et al. (2018).

The results of inter-comparisons between the $\sigma_{s c a}$ values measured by the nephelometer and those calculated using the Mie scattering model are shown in Fig. S1. We observed strong consistency between the measured and calculated $\sigma_{s c a}$ values $\left(R^{2}=0.99\right.$ for different wavelengths), which indicated that the aerosol PNSD and $\sigma_{s c a}$ measurements by the nephelometer were reliable. Because the $\sigma_{s c a}$ values measured using the nephelometer in the present study were raw measured data, and truncation error corrections were not conducted, the calculated $\sigma_{s c a}$ values were always slightly larger than the measured values, with regressed larger regression slope than unity for each wavelength.

The measured $\sigma_{s c a}$ values using the PASS-3 and the nephelometer at similar wavelengths were compared. The measured $\sigma_{s c a}$ were adjusted to the same wavelength using the scattering Ångström exponent. Our findings are presented in Fig. S2 and show that great consistency was achieved between $\sigma_{s c a}$ values at $525 \mathrm{~nm}$ from the nephelometer and $\sigma_{\text {sca }}$ from the PASS-3. The slope (1.06) was slightly higher than 1.0, which was mainly caused by the different truncation errors between nephelometer and PASS-3. The $\sigma_{s c a}$ values measured at other wavelengths had almost the same trends $\left(\mathrm{R}^{2}>0.99\right)$. Our inter-comparison of the $\sigma_{\text {sca }}$ values measured by the PASS-3 and nephelometer demonstrated that the measurements of both instruments were reliable.

Finally, $\sigma_{s c a}$ values were measured by PASS- 3 and calculated using the Mie scattering model at wavelengths of 405, 532, and $781 \mathrm{~nm}$; the results were compared and presented in Fig. 2. Notably, the measured and calculated $\sigma_{\text {sca }}$ values exhibited strong consistency. The relative difference between them was primarily less than $20 \%$.

Overall, the closures achieved between the measured $\sigma_{s c a}$ values by the PASS-3, the measured $\sigma_{s c a}$ values by the nephelometer and the calculated $\sigma_{s c a}$ values by the Mie scattering model demonstrated that the PASS-3 provided $\sigma_{s c a}$ values with high accuracy. Therefore, the measured $\sigma_{a b s}$ by the PASS-3 was reliable. We thus used the measured $\sigma_{a b s}$ by the PASS-3 as a reference for the other instruments.

\section{$\sigma_{A T N}$ Properties of Different Filter Tapes in AE33 Instruments}

Two AE33 instruments (AE33-345 and AE33-582) were used to measure $\sigma_{A T N}$ using Filter Tapes 8050 and 8060, respectively. Notably, the $\sigma_{A T N}$ values obtained from the AE33 used in the present study were different from the $\sigma_{a b s}$ values by a factor of $\mathrm{C}_{f}$. As shown in Table $\mathrm{S} 1$, four intercomparisons were conducted to evaluate the performance of Filter Tapes 8050 and 8060 . The $\sigma_{A T N}$ values measured from the AE33-345 and AE33-582 were compared using (1) Tape 8060 and Tape 8060 from March 20 to April 24; (2) Tape 8050 and Tape 8060 from March 24 to April 30; (3) Tape 8060 and Tape 8050 from October 10 to October 15; and (4) Tape 8050 and Tape 8050 from October 15 to October 19.

Figs. 3(a), 3(b), 3(c) and 3(d) present a comparison of the measured $\sigma_{A T N}$ values in Table S1 at $880 \mathrm{~nm}$ for Groups (1), (2), (3), and (4), respectively. According to Fig. 3(a), the $\sigma_{\text {ATN }}$ values from the two instruments with Tape 8060 exhibited strong agreement $\left(\mathrm{R}^{2}=0.99\right.$, slope $\left.=1.08\right)$. Moreover, almost all of the $\sigma_{A T N}$ values from the two instruments had a relative difference of less than $20 \%$. However, the consistency between $\sigma_{A T N}$ values from the two instruments decreased when one of the instruments switched to Tape $8050\left(\mathrm{R}^{2}=\right.$ 0.95 and 0.97 for Test Groups [2] and [3], respectively). The slopes of 1.13 and 1.12 demonstrate that the $\sigma_{A T N}$ values measured by the AE33-582 is about 1.1 times that of measured value by the AE33-345. However, when both instruments switched to Tape 8050 , the consistency between $\sigma_{A T N}$ values worsened $\left(R^{2}=0.87\right)$; in many cases, the relative difference between the measured $\sigma_{A T N}$ values was greater than $20 \%$. Overall, the relative difference in $\sigma_{A T N}$ values between the two instruments did not indicate a clear relationship with the ATN values. Thus, the stability of the measured $\sigma_{A T N}$ values were not improved by changing the tape more frequently.

Our inter-comparison results suggested that the $\sigma_{A T N}$ values measured by Tape 8060 was more stable than that measured by Tape 8050 . Nonetheless, a relative difference of $10 \%$ still existed among different AE instruments.

The $\alpha_{a b s}$ value was calculated using Eq. (1) with the $\sigma_{A T N}$ values at $470 \mathrm{~nm}$ and $950 \mathrm{~nm}$ measured using the AE33, which can be used as the source attribution for traffic and wood burning (Martinsson et al., 2017; Zotter et al., 2017).

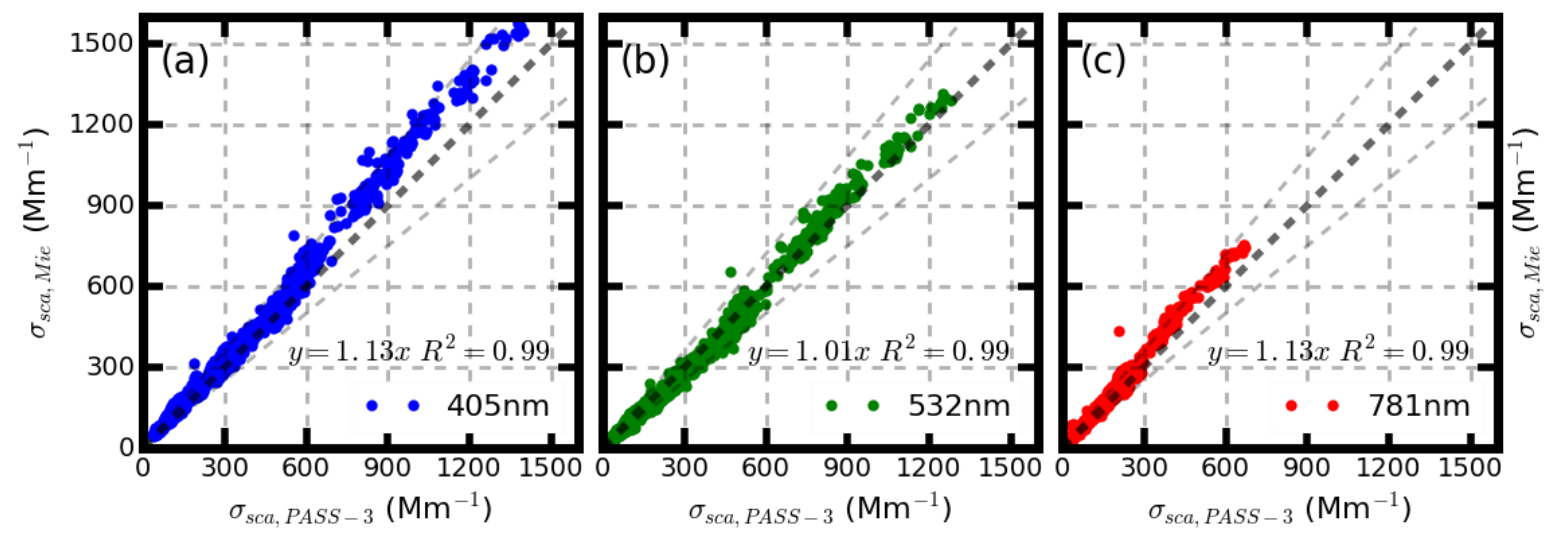

Fig. 2. Comparison of the $\sigma_{\text {sca }}$ measured using the PASS-3 and calculated using the Mie scattering model at wavelength of (a) $405 \mathrm{~nm}$, (b) $532 \mathrm{~nm}$ and (c) $781 \mathrm{~nm}$. The dashed lines in each panel represent 1:1 and a relative difference of $20 \%$. 


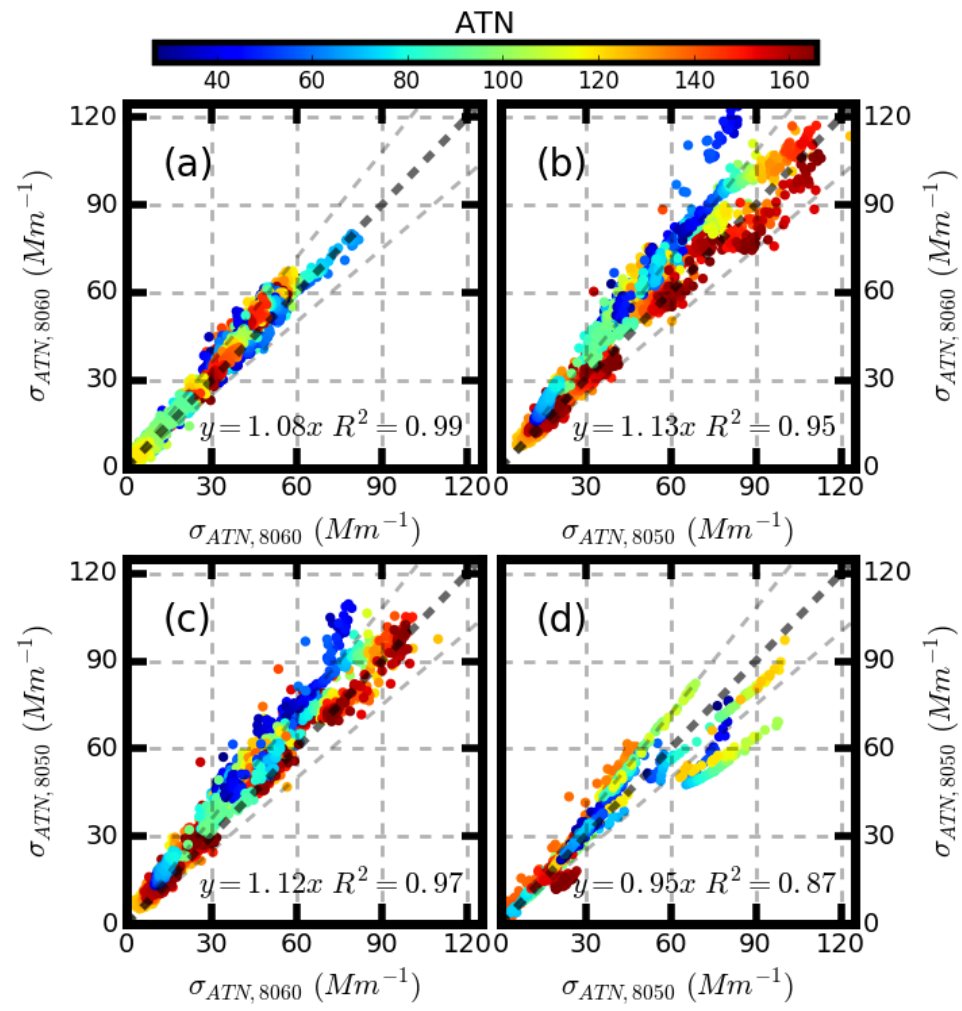

Fig. 3. Comparison of the $\sigma_{a b s}$ at $880 \mathrm{~nm}$ measured using the AE33. The $\sigma_{a b s}$ values on the $\mathrm{x}$ and y axes were measured using the AE33-345 and AE33-582 respectively. Each panel shows comparisons of using (a) Tape 8060 versus Tape 8060 , (b) Tape 8050 versus Tape 8060, (c) Tape 8060 versus Tape 8050 and (d) Tape 8050 versus Tape 8050.

The discussion in Section 3.3 reveals that the calculated $\alpha_{a b s}$ values from $\sigma_{A T N}$ and $\sigma_{a b s}$ were the same. The measured $\alpha_{a b s}$ values at different accumulated ATNs and on different days using Tape 8050 and Tape 8060 are shown in Figs. 4(a) and 4(b), respectively. The calculated $\alpha_{a b s}$ values from Tape 8060 (Fig. 4(b)) did not exhibit a clear relationship with accumulated ATN, and the variations in $\alpha_{a b s}$ were mainly a result of the diversity in ambient aerosol absorption properties. However, the $\alpha_{a b s}$ from Tape 8050 was highly correlated with the ATN values shown in Fig. 4(a). When the ATN changed from 22-60 to 120 , the mean $\alpha_{a b s}$ values changed from $1.6-1.8$ to 2.0 , respectively. However, the variation in $\alpha_{a b s}$ was approximately 0.6 , which is almost the same degree of $\alpha_{a b s}$ variation caused by different ATNs when using Tape 8050. Therefore, the $\alpha_{a b s}$ value measured using the AE33 using Tape 8050 was associated with great uncertainty.

The $\alpha_{a b s}$ at the Taizhou site had almost the same properties as that at the PKU site, as shown in Fig. S3. The results indicated that $\alpha_{a b s}$ changed significantly with the ATN for Tape 8050 , but that there were no clear variations with the increased accumulation of ATN for Tape 8060.

\section{Multiple-scattering Correction Factor}

The PASS-3 estimated the instrument noise and recorded the value in its reported data. The statistical results for noise during the measurement are shown in Fig. S4. The mean and standard deviation of $\sigma_{a b s}$ for instrument noise were 0.34 and 0.066 , respectively, with a $95.5 \%$ possibility (sum of the mean and double the standard deviation) that the noise was less

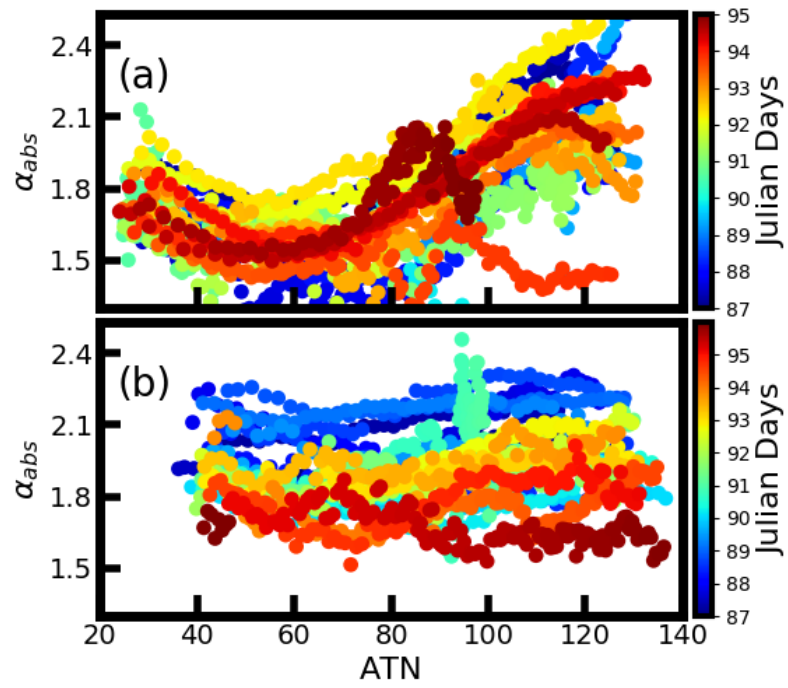

Fig. 4. Measured $\alpha_{a b s}$ values at different ATNs for (a) Tape 8050 and (b) Tape 8060 at the PKU site. The dots with almost the same color and small difference in ATN share the same tape spot. The number in the color bar represents the Julian days in 2018.

than 0.473 . To confirm that the measured $\sigma_{a b s}$ noise comprised a small partition of the measured $\sigma_{a b s}$, we compared these data when the surrounding $\sigma_{a b s}$ was larger than $10.50 \mathrm{Mm}^{-1}$ $[0.473 /(1-95.5 \%)]$, under which condition the noise would account for less than $4.5 \%$ of the measured $\sigma_{a b s}$ value. 
Figs. 5(a), 5(b), and 5(c) present a comparison of the $\sigma_{a b s}$ values measured using the PASS- 3 and the $\sigma_{A T N}$ values by the AE33 at wavelengths of 405, 532, and $781 \mathrm{~nm}$, respectively, at the PKU site. Section 3.2 reveals that the measured results of the AE33 with Tape 8060 were more reliable and stable than those from the AE33 with Tape 8050. Thus, the $\sigma_{A T N}$ value from the AE33 with Tape 8060 was used for comparison. The $\sigma_{A T N}$ value at $405 \mathrm{~nm}$ was calculated using the $\alpha_{A T N}$ value that had been previously calculated using the $\sigma_{A T N}$ values at $370 \mathrm{~nm}$ and $470 \mathrm{~nm}$. The corresponding $\sigma_{A T N}$ values of AE33 at 532 and $781 \mathrm{~nm}$ were calculated using the $\sigma_{A T N}$ values at the wavelength pairs of 520 and $590 \mathrm{~nm}$, and 660 and $880 \mathrm{~nm}$, respectively. $\sigma_{a b s}$ can be derived by dividing $\sigma_{A T N}$ by $\mathrm{C}_{f}$. Here, $\mathrm{C}_{f}$ was determined by calculating the ratio of the $\sigma_{A T N}$ values measured using the AE33 and the $\sigma_{a b s}$ values measured using the PASS-3. As revealed in Fig. 5, $\mathrm{C}_{f}$ was determined to be 2.91, 2.94 and 2.94 at 405, 532, and $781 \mathrm{~nm}$, respectively, by using the linear regression forcing the intercept to zero. $\mathrm{C}_{f}$ did not exhibit obvious variations with changes in wavelength. The comparison was conducted for the Taizhou site and the corresponding $\mathrm{C}_{f}$ values were $2.88,2.88$ and 2.86 at 405,532 , and $781 \mathrm{~nm}$, respectively, as shown in Fig. S5. The $\mathrm{C}_{f}$ value is smaller than that of 4.35 in central Oregon, USA (Laing et al., 2020).

Therefore, the $\mathrm{C}_{f}$ was recommended to be $2.90( \pm 0.04)$ for both sites, which is an average of all the ratios. Notably, this value was the same for different wavelengths.

\section{Correction Method of $\sigma_{A T N}$}

According to the findings presented in Section 3.3, it is clear that the AE33 with Tape 8060 provided a reliable $\sigma_{a b s}$ measurement with a $\mathrm{C}_{f}$ value of 2.90 . By contrast, the $\sigma_{A T N}$ and $\alpha_{a b s}$ values measured with Tape 8050 were related to the accumulation of ATN (see Section 3.2). Moreover, the $\sigma_{A T N}$ values measured with Tape 8060 was relatively stable and unrelated to the accumulation of ATN. However, because the AE33 with Tape 8050 has long been used worldwide for measuring ambient $\mathrm{BC}$ mass loadings, historical observation data from the AE33 with Tape 8050 should be corrected. We propose a straightforward method to correct $\sigma_{A T N}$ values measured with Tape 8050 on the basis of $\sigma_{A T N}$ values measured with Tape 8060 .
First, the $\sigma_{A T N}$ values measured with Tape 8050 were grouped according to their ATN values from 20 to 140 with a step of 5 . We also recorded the concurrently measured $\sigma_{A T N}$ values from Tape 8060 . For each group, the $\sigma_{A T N}$ values measured with 8050 and 8060 were compared and the regression slope value was used as the correction factor for the $\sigma_{A T N}$ values measured with Tape 8050 .

Fig. 6 shows the correction factors at different wavelengths and ATN values, revealing that the correction factors varied significantly with the amount of ATN. When the ATN was less than 80, the correction factors did not exhibit clear differences among different wavelengths. They did, however, become increasingly diverse across different wavelengths as ATN increased. The $\sigma_{A T N}$ values measured with Tape 8050 were slightly lower than those measured with Tape 8060 when the ATN was less than 90 across the seven wavelengths.

Because the correction factors were different for different wavelengths, we calculated the difference in $\alpha_{a b s}$ values at the wavelengths of $470 \mathrm{~nm}$ and $950 \mathrm{~nm}$. The results, presented in Fig. 6, indicated that corrections of $\sigma_{A T N}$ can lead to variations in $\alpha_{a b s}$ from $0.02-0.15$ to 0.23 when ATN increased from $30-60$ to 130 . The variations in $\alpha_{a b s}$ were consistent with the results presented in Section 3.2, namely that the measured $\alpha_{a b s}$ values first decreased and then increased with the increase in ATN. This suggests that the correction factors can provide a more reliable $\sigma_{A T N}$ and $\alpha_{a b s}$ values for Tape 8050 .

Fig. 7 provides one example of the effects of correction on the measured $\sigma_{A T N}$ and $\alpha_{a b s}$ values. Specifically, Figs. 7(a) and 7(b) show the raw and corrected $\sigma_{A T N}$ values at wavelengths 470, 590, and $950 \mathrm{~nm}$. Figs. 7(c) and 7(d) display the corresponding $\alpha_{a b s}$ values calculated from Figs. 7(a) and 7(b) using the respective wavelengths of 470 and $950 \mathrm{~nm}$. The location at which the tape was switched can be recognized directly when the ATN decreased from higher than 135 to less than 40, as shown in Figs. 7(c) and 7(d). Figs. 7(a) and 7 (c) reveal that both $\sigma_{A T N}$ and $\alpha_{a b s}$ exhibited large discrepancies when the tape was switched for the raw measured $\sigma_{A T N}$. However, the situation improved when $\sigma_{A T N}$ was corrected using the factors shown in Fig. 6, resulting in more continuous $\sigma_{A T N}$ and $\alpha_{a b s}$ values than before.

In conclusion, two steps of correction should be applied
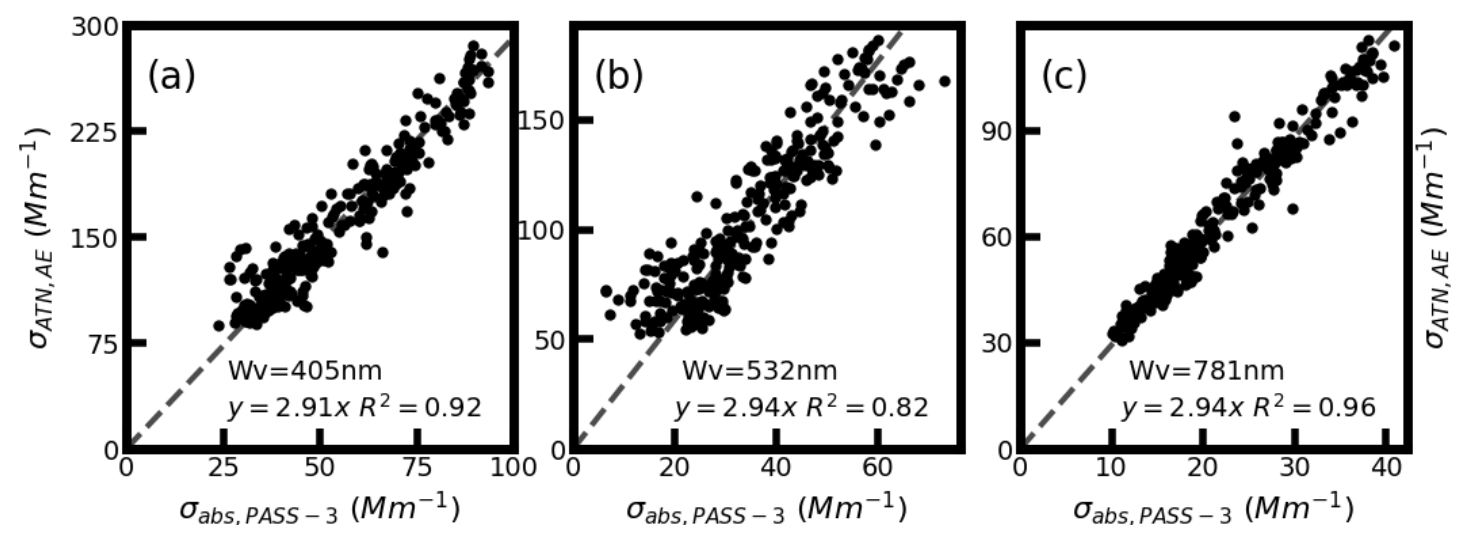

Fig. 5. Comparison between the $\sigma_{a b s}$ values measured using the PASS-3 and $\sigma_{A T N}$ values measured using the AE33 at (a) $405 \mathrm{~nm}$, (b) $532 \mathrm{~nm}$ and (c) $781 \mathrm{~nm}$ at the PKU site. 


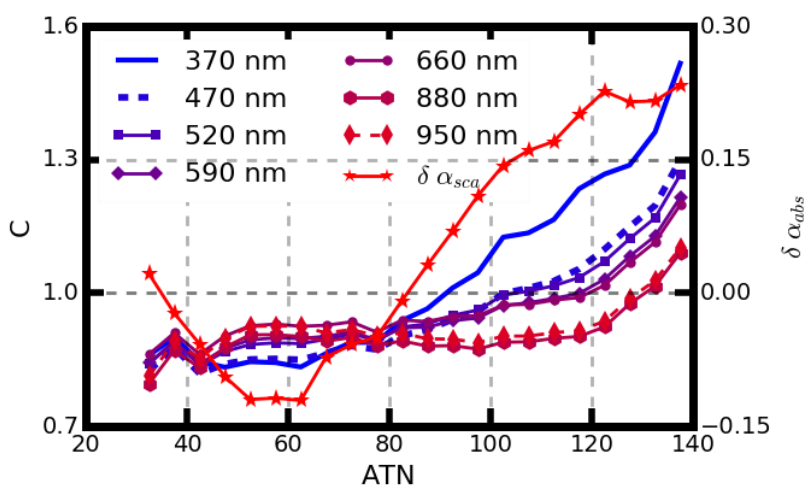

Fig. 6. Correction factors for the $\sigma_{A T N}$ measured using Tape 8050 for different wavelengths and the corresponding variations in $\alpha_{a b s}$ of $470 \mathrm{~nm}$ and $950 \mathrm{~nm}$ at different ATNs.

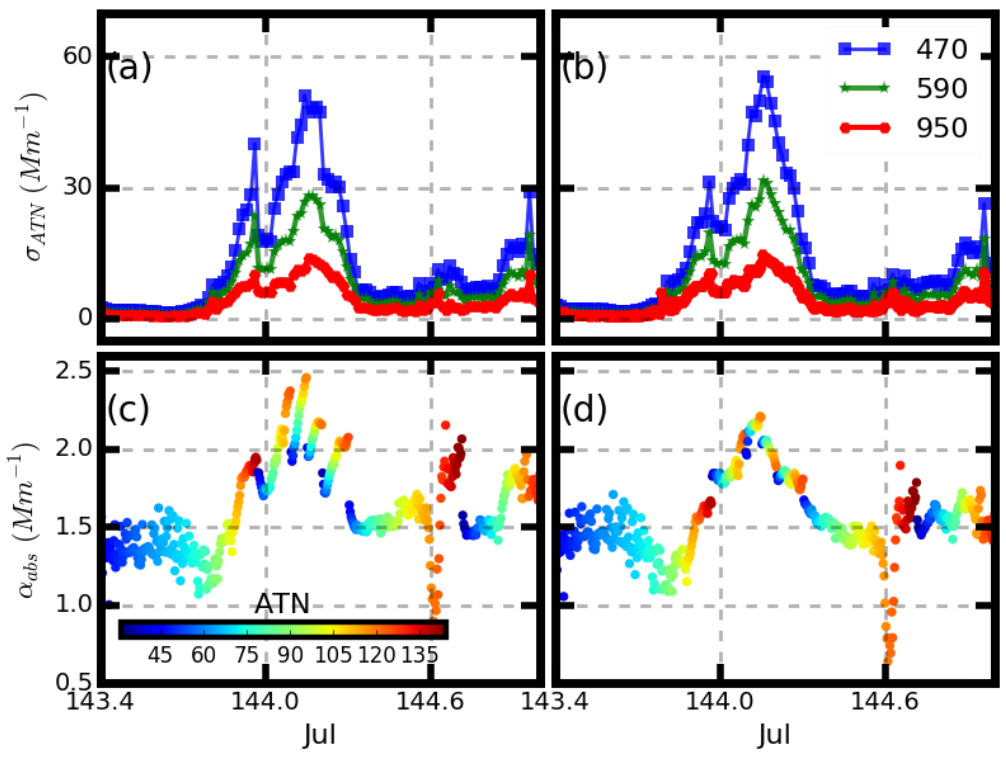

Fig. 7. (a-b) The $\sigma_{A T N}$ and (c-d) $\alpha_{a b s}$ time series: (a) and (c) show the raw data, (b) and (d) show the corrected data, (a) and (c) share the same color bar, and (b) and (d) share the same wavelengths.

for $\sigma_{A T N}$ values measured with Tape 8050 . The first step is to correct the measured $\sigma_{A T N}$ values by the factor shown in Fig. 6 for different ATNs and wavelengths. The second step is the same as that used for correction for Tape 8060: correcting the multiple-scattering effects by using a recommended factor of 2.9 for each wavelength.

\section{CONCLUSIONS}

In this study, we evaluated the reliability of $\sigma_{a b s}$ values measured with an AE33 during two field campaigns in Taizhou and at PKU. Comparing the values measured with two different AE33s, one using Tape 8050 and the other using Tape 8060 , we found that using Tape 8060 produced more stable $\sigma_{A T N}$ values.

As no clear relationship between the $\alpha_{a b s}$ and the ATN was observed, the loading effects were apparently sufficiently corrected for Tape 8060; thus, only the multiple-scattering correction should be applied when measuring $\sigma_{A T N}$ values with this tape. However, since the loading effects were not adequately corrected for Tape 8050 , both the loading effect and multiple-scattering corrections for $\sigma_{A T N}$ should be considered when using this tape.

Based on the comparison between the $\sigma_{a b s}$ values measured with the PASS-3 and the $\sigma_{A T N}$ values measured with the AE33 using Tape 8060, we recommend a mean $\mathrm{C}_{f}$ value of $2.9 \pm 0.4$ to correct the measured $\sigma_{A T N}$ independent of wavelength. We also obtained a correction factor for the $\sigma_{A T N}$ measured using Tape 8050 by regressing values measured using Tape 8060 against those measured using Tape 8050 for different ATNs and wavelengths. This factor corrected the discrepancy in the measured $\sigma_{A T N}$ between the tape sampling values and the raw data, thereby resolving $\alpha_{a b s}$ 's variation with the ATN.

This study can serve as a reference for $\sigma_{a b s}$ measurements and for source appointments. Using one correction factor for the North and East China Plain offered the advantage of increasing the inter-comparability of the measurements from different sites and facilitating the reconstruction of the AE33-measured historical observation data. 


\section{DATA AVAILABILITY}

The measurement data involved in this study are available upon request.

\section{ACKNOWLEDGMENTS}

This work was supported by the National Key R\&D Program of China (2016YFC020000: Task 5, Task 3) and the National Natural Science Foundation of China (41875044, 41675038, 21677002).

\section{COMPETING INTERESTS}

The authors declare that they have no conflict of interest.

\section{SUPPLEMENTARY MATERIAL}

Supplementary data associated with this article can be found in the online version at http://www.aaqr.org.

\section{REFERENCES}

Ångström, A. (1929). On the atmospheric transmission of sun radiation and on dust in the air. Geogr. Ann. 11: 156166. https://doi.org/10.1080/20014422.1929.11880498

Arnott, W.P., Hamasha, K., Moosmüller, H., Sheridan, P.J. and Ogren, J.A. (2005). Towards aerosol light-absorption measurements with a 7-wavelength aethalometer: Evaluation with a photoacoustic instrument and 3wavelength nephelometer. Aerosol Sci. Technol. 39: 1729. https://doi.org/10.1080/027868290901972

Bohren, C.F. and Huffman, D.R. (2007). Absorption and scattering by a sphere. $\mathrm{n}$ Absorption and scattering of light by small particles, Wiley-VCH Verlag GmbH, pp. 82-129. https://doi.org/10.1002/9783527618156.ch4

Bond, T.C., Anderson, T.L. and Campbell, D. (1999). Calibration and intercomparison of filter-based measurements of visible light absorption by aerosols. Aerosol Sci. Technol. 30: 582-600. https://doi.org/10.10 80/027868299304435

Bond, T.C., Doherty, S.J., Fahey, D.W., Forster, P.M., Berntsen, T., DeAngelo, B.J., Flanner, M.G., Ghan, S., Karcher, B., Koch, D., Kinne, S., Kondo, Y., Quinn, P.K., Sarofim, M.C., Schultz, M.G., Schulz, M., Venkataraman, C., Zhang, H., Zhang, S., Bellouin, N., Guttikunda, S.K., Hopke, P.K., Jacobson, M.Z., Kaiser, J.W., Klimont, Z., Lohmann, U., Schwarz, J.P., Shindell, D., Storelvmo, T., Warren, S.G. and Zender, C.S. (2013). Bounding the role of black carbon in the climate system: A scientific assessment. J. Geophys. Res. 118: 5380-5552. https://doi. org/10.1002/jgrd.50171

Coen, M.C., Weingartner, E., Apituley, A., Ceburnis, D., Fierzschmidhauser, R., Flentje, H., Henzing, J.S., Jennings, S.G., Moerman, M. and Petzold, A. (2010). Minimizing light absorption measurement artifacts of the aethalometer: Evaluation of five correction algorithms. Atmos. Meas. Tech. 3: 457-474. https://doi.org/10.5194/amt-3-457-2010 Cremer, J.W., Covert, P.A., Parmentier, E.A. and Signorell,
R. (2017). Direct measurement of photoacoustic signal sensitivity to aerosol particle size. J. Phys. Chem. Lett. 8: 3398-3403. https://doi.org/10.1021/acs.jpclett.7b01288

Davies, N.W., Cotterell, M.I., Fox, C., Szpek, K., Haywood, J.M. and Langridge, J.M. (2018). On the accuracy of aerosol photoacoustic spectrometer calibrations using absorption by ozone. Atmos. Meas. Tech. 11: 2313-2324. https://doi.org/10.5194/amt-11-2313-2018

Drinovec, L., Močnik, G., Zotter, P., Prévôt, A.S.H., Ruckstuhl, C., Coz, E., Rupakheti, M., Sciare, J., Müller, T., Wiedensohler, A. and Hansen, A.D.A. (2015). The "dual-spot" aethalometer: An improved measurement of aerosol black carbon with real-time loading compensation. Atmos. Meas. Tech. 8: 1965-1979. https://doi.org/10.514 /amt-8-1965-2015

Guo, S., Hu, M., Guo, Q., Zhang, X., Zheng, M., Zheng, J., Chang, C.C., Schauer, J.J. and Zhang, R. (2012). Primary sources and secondary formation of organic aerosols in Beijing, China. Environ. Sci. Technol. 46: 9846-9853. https://doi.org/10.1021/es2042564

Guo, S., Hu, M., Guo, Q., Zhang, X., Schauer, J.J. and Zhang, R. (2013). Quantitative evaluation of emission controls on primary and secondary organic aerosol sources during Beijing 2008 olympics. Atmos. Chem. Phys. 13: 8303-8314. https://doi.org/10.5194/acp-13-8303-2013

Hansen, A.D.A., Rosen, H. and Novakov, T. (1984). The aethalometer - An instrument for the real-time measurement of optical absorption by aerosol particles. Sci. Total Environ. 36: 191-196. https://doi.org/10.1016/ 0048-9697(84)90265-1

Koch, D. and Del Genio, A.D. (2010). Black carbon semidirect effects on cloud cover: Review and synthesis. Atmos. Chem. Phys. 10: 7685-7696. https://doi.org/10.51 94/acp-10-7685-2010

Kuang, Y., Zhao, C.S., Tao, J.C. and Ma, N. (2015). Diurnal variations of aerosol optical properties in the north china plain and their influences on the estimates of direct aerosol radiative effect. Atmos. Chem. Phys. 15: 57615772. https://doi.org/10.5194/acp-15-5761-2015

Lack, D.A., Moosmueller, H., McMeeking, G.R., Chakrabarty, R.K. and Baumgardner, D. (2014). Characterizing elemental, equivalent black, and refractory black carbon aerosol particles: A review of techniques, their limitations and uncertainties. Anal. Bioanal.Chem. 406: 99-122. https://doi.org/10.1007/s00216-013-7402-3

Laing, J.R., Jaffe, D.A. and Sedlacek, III. A.J. (2020). Comparison of filter-based absorption measurements of biomass burning aerosol and background aerosol at the mt. Bachelor observatory. Aerosol Air Qual. Res. 20: 663-678. https://doi.org/10.4209/aaqr.2019.06.0298

Martinsson, J., Abdul Azeem, H., Sporre, M., Bergström, R., Ahlberg, E., Öström, E., Kristensson, A., Swietlicki, E. and Stenström, K. (2017). Carbonaceous aerosol source apportionment using the Aethalometer model - evaluation by radiocarbon and levoglucosan analysis at a rural background site in southern Sweden. Atmos. Chem. Phys. 17: 4265-4281. https://doi.org/10.5194/acp-17-4265-2017

Masey, N., Ezani, E., Gillespie, J., Sutherland, F., Lin, C., Hamilton, S., Heal, M.R. and Beverland, I.J. (2020). 
Consistency of urban background black carbon concentration measurements by portable AE51 and reference AE22 aethalometers: Effect of corrections for filter loading. Aerosol Air Qual. Res. 20: 329-340. https://doi.org/10.4209/aaqr.2019.03.0145

Moosmüller, H., Arnott, W.P., Rogers, C.F., Chow, J.C., Frazier, C.A., Sherman, L.E. and Dietrich, D.L. (1998). Photoacoustic and filter measurements related to aerosol light absorption during the Northern Front Range Air Quality Study (Colorado 1996/1997). J. Geophys. Res. 103: 28149-28157. https://doi.org/10.1029/98JD02618

Müller, T., Laborde, M., Kassell, G. and Wiedensohler, A. (2011). Design and performance of a three-wavelength LED-based total scatter and backscatter integrating nephelometer. Atmos. Meas. Tech. 4: 1291-1303. https://doi.org/10.5194/amt-4-1291-2011

Nakayama, T., Suzuki, H., Kagamitani, S., Ikeda, Y., Uchiyama, A. and Matsumi, Y. (2015). Characterization of a three wavelength photoacoustic soot spectrometer (PASS-3) and a photoacoustic extinctiometer (PAX). $J$. Meteorolog. Soc. Jpn. 3: 285-308. https://doi.org/10.215 1/jmsj.2015-016

Petzold, A. and Schönlinner, M. (2004). Multi-angle absorption photometry - a new method for the measurement of aerosol light absorption and atmospheric black carbon. $J$. Aerosol Sci. 35: 421-441. https://doi.org/10.1016/j.jaeros ci.2003.09.005

Petzold, A., Ogren, J.A., Fiebig, M., Laj, P., Li, S.M., Baltensperger, U., Holzer-Popp, T., Kinne, S., Pappalardo, G., Sugimoto, N., Wehrli, C., Wiedensohler, A. and Zhang, X.Y. (2013). Recommendations for reporting "black carbon" measurements. Atmos. Chem. Phys. 13: 83658379. https://doi.org/10.5194/acp-13-8365-2013

Saturno, J., Pöhlker, C., Massabò, D., Brito, J., Carbone, S., Cheng, Y., Chi, X., Ditas, F., Hrabě de Angelis, I., MoránZuloaga, D., Pöhlker, M.L., Rizzo, L.V., Walter, D., Wang, Q., Artaxo, P., Prati, P. and Andreae, M.O. (2017). Comparison of different aethalometer correction schemes and a reference multi-wavelength absorption technique for ambient aerosol data. Atmos. Meas. Tech. 10: 28372850. https://doi.org/10.5194/amt-10-2837-2017

Schmid, O., Artaxo, P., Arnott, W.P., Chand, D., Gatti, L.V., Frank, G.P., Hoffer, A., Schnaiter, M. and Andreae, M.O. (2006). Spectral light absorption by ambient aerosols influenced by biomass burning in the amazon basin. I: Comparison and field calibration of absorption measurement techniques. Atmos. Chem. Phys. 6: 3443-3462. https://doi.org/10.5194/acp-6-3443-2006

Sharma, S., Leaitch, W.R., Huang, L., Veber, D., Kolonjari, F., Zhang, W., Hanna, S.J., Bertram, A.K. and Ogren, J.A. (2017). An evaluation of three methods for measuring black carbon in Alert, Canada. Atmos. Chem. Phys. 17: 15225-15243. https://doi.org/10.5194/acp-17-15225-2017

Tang, R., Wu, Z., Xiao, L., Wang, Y., Shang, D., Yao, X., Li, M., Zeng, L., Wu, Z. and Hallquist, M. (2018).
Primary and secondary organic aerosols in summer 2016 in Beijing. Atmos. Chem. Phys. 18: 4055-4068. https://doi.org/10.5194/acp-18-4055-2018

Terhune, R.W. and Anderson, J.E. (1977). Spectrophone measurements of the absorption of visible light by aerosols in the atmosphere. Opt. Lett. 1: 70. https://doi.org/ 10.1364/OL.1.000070

Utry, N., Ajtai, T., Filep, Á., Pintér, M., Török, Z., Bozóki, Z. and Szabó, G. (2014). Correlations between absorption Angström exponent (AAE) of wintertime ambient urban aerosol and its physical and chemical properties. Atmos. Environ. 91: 52-59. https://doi.org/10.1016/j.atmosenv.2 014.03.047

Virkkula, A., Chi, X., Ding, A., Shen, Y., Nie, W., Qi, X., Zheng, L., Huang, X., Xie, Y., Wang, J., Petaja, T. and Kulmala, M. (2015). On the interpretation of the loading correction of the aethalometer. Atmos. Meas. Tech. 8: 4415-4427. https://doi.org/10.5194/amt-8-4415-2015

Wex, H., Neusüß, C., Wendisch, M., Stratmann, F., Koziar, C., Keil, A., Wiedensohler, A. and Ebert, M. (2002). Particle scattering, backscattering, and absorption coefficients: An in situ closure and sensitivity study. $J$. Geophys. Res. 107: LAC 4-1-LAC 4-18. https://doi.org/ 10.1029/2000JD000234

Wilcox, E.M., Thomas, R.M., Praveen, P.S., Pistone, K., Bender, F.A.M. and Ramanathan, V. (2016). Black carbon solar absorption suppresses turbulence in the atmospheric boundary layer. Proc. Natl. Acad. Sci. U.S.A. 113: 11794 11799. https://doi.org/10.1073/pnas.1525746113

Zhao, G., Zhao, C., Kuang, Y., Bian, Y., Tao, J., Shen, C. and $\mathrm{Yu}, \mathrm{Y}$. (2018). Calculating the aerosol asymmetry factor based on measurements from the humidified nephelometer system. Atmos. Chem. Phys. 18: 90499060. https://doi.org/10.5194/acp-18-9049-2018

Zhao, G., Tan, T., Zhao, W., Guo, S., Tian, P. and Zhao, C. (2019a). A new parameterization scheme for the real part of the ambient urban aerosol refractive index. Atmos. Chem. Phys. 19: 12875-12885. https://doi.org/10.5194/a cp-19-12875-2019

Zhao, G., Tao, J., Kuang, Y., Shen, C., Yu, Y. and Zhao, C. (2019b). Role of black carbon mass size distribution in the direct aerosol radiative forcing. Atmos. Chem. Phys. 19: 13175-13188. https://doi.org/10.5194/acp-19-13175-2019

Zotter, P., Herich, H., Gysel, M., El-Haddad, I., Zhang, Y., Močnik, G., Hüglin, C., Baltensperger, U., Szidat, S. and Prévôt, A.S.H. (2017). Evaluation of the absorption Ångström exponents for traffic and wood burning in the aethalometer-based source apportionment using radiocarbon measurements of ambient aerosol. Atmos. Chem. Phys. 17: 4229-4249. https://doi.org/10.5194/acp-17-4229-2017

Received for review, November 22, 2019 Revised, February 4, 2020 Accepted, April 2, 2020 